\title{
Anodized Aluminium Oxide Coating for Sensitive Sensing of Folic acid in Vegetables and Control of Dyeing
}

\author{
Fu-Cheng Chiang ${ }^{1}$, Cheng-Chien Chang ${ }^{2}$, Shen-Ming Chen ${ }^{3, *}$, Tse-Wei Chen ${ }^{3}$, Mani Govindasamy , \\ Heh-Jiun Yang ${ }^{l}$
}

${ }^{1}$ Engineer, Technical Service for Anodized Aluminum, Everlight Chemical Industrial Corporation Plant 1, No.271, Zhong-Shan N. Rd., Dayuan Industrial Park, Tao-Yuan Country 337, Taiwan.

2 Asst. Manager, Technical Service for Anodized Aluminum, Everlight Chemical Industrial Corporation Plant 1, No.271, Zhong-Shan N. Rd., Dayuan Industrial Park, Tao-Yuan Country 337, Taiwan.

3 Electroanalysis and Bioelectrochemistry Lab, Department of Chemical Engineering and Biotechnology, National Taipei University of Technology, No.1, Section 3, Chung-Hsiao East Road, Taipei 106. Taiwan (ROC).

*E-mail: smchen78@ms15.hinet.net.

doi: $10.20964 / 2018.05 .71$

Received: 22 January 2018 / Accepted: 15 March 2018 / Published: 10 April 2018

\begin{abstract}
Aluminum electrochemical anodizing dyed products have been widely used in various sectors of industries including cell phone, laptop computers, bikes and aero-space technologies. During the process of aluminum electrochemical anodizing dyeing industry, and waste water which contains dyestuffs tend to be emitted and most of them comes from the color bleeding during the process of sealing; therefore, the topic of how to reduce the color bleeding efficiency during the sealing process and decrease dyed waste water generated becomes a huge environmental issue. In the research, the factors which cause the color bleeding during the sealing process are thoroughly discussed and ratified in a careful manner. Statistical analysis is conducted to analyze how color bleeding is influenced by different dyeing temperatures and various film thickness formed in different time frame of aluminum electrochemical anodizing dyeing. Moreover, aluminum electrochemical anodizing electrode carried out into electrochemical process; the porous oxide film modified electrode is employed to detection of folic acid (FA) in vegetables. The sensor linear range is 0.1 to $897 \mu \mathrm{M}, \mathrm{LOD}=54 \mathrm{nM}$, and sensitivity is $5.18 \mu \mathrm{A} \mu \mathrm{M}^{-1} \mathrm{~cm}^{-2}$.
\end{abstract}

Keywords: Electrochemical, Alumina, anodization, dyeing, sealing process, folic acid, vegetables sample, porous materials.

\section{FULL TEXT}


(C) 2018 The Authors. Published by ESG (www.electrochemsci.org). This article is an open access article distributed under the terms and conditions of the Creative Commons Attribution license (http://creativecommons.org/licenses/by/4.0/). 